\title{
Philosophy of Information and Fundamental Problems of Modern Informatics
}

\author{
Konstantin Kolin
}

kolinkk@mail.ru, The Institute of Informatics Problems of the Russian Academy of Sciences, Moscow, Russia

\begin{abstract}
Actual philosophical and scientifically methodological problems of modern Informatics as fundamental science and a complex scientific direction are considered. Communication of these problems with prospects of development of Informatics and fundamental science as a whole is shown.
\end{abstract}

Keywords: philosophy of information, modern Informatics, the fundamental problem

\section{Relevance of the Problem}

In recent years, the role of Informatics as basic science and a complex scientific field has increased. This is because the very logic of modern science, which includes a new scientific paradigm and new research methodology, is based on the use of concepts and methods of Informatics. One of the most pressing challenges is the need to study the conceptual nature of information as one of the manifestations of objective reality.

Today, scientists doing research on many traditional areas of science (physics, chemistry, earth sciences, biology, sociology, psychology, etc.) are increasingly faced with the need to take into account the information of their study sites, processes and phenomena and are, therefore, very interested in using new tools and methods of Informatics. Information and network technologies, methods and tools for information modeling and an informational approach as a method of scientific knowledge are among the most important of these. The whole methodology of modern science is much more information-oriented then it was, in the previous century.

Therefore, Informatics is not only a rapidly developing and promising area of modern science, but also a fundamental component of the process of scientific knowledge, and the scientific basis for the formation of a knowledge-based society. In this regard, there is increased interest in understanding the grounds of Informatics, as well as its philosophical and scientific and methodological aspects, observed in science and education.

Educational systems in many countries today are experiencing a new phase of radical modernization. The goal is to significantly improve the quality of education, formation of the modern scientific worldview and the new personal information culture. This, in turn, requires a shift in the educational system to the new principles of studying Informatics as basic science and in general education courses. The combination of research results obtained by Russian scientists in recent decades, could become the basis for the formation of a new paradigm of education that takes into account the need to use the latest achievements and capabilities of information technology in virtually all spheres of social activity.

\section{Philosophy of Information and Philosophical Problems of Informatics}

The philosophy of information has developed in Russia for more than 40 years. Here academician A.D. Ursul first noted the basic research problems. His books, published more than 30 years ago, are classical works in this area and are well known to specialists. They remain relevant today, as the philosophical problems of information and Informatics are increasingly discussed in the pages of scientific journals and conferences.

A good incentive for paying attention to philosophical problems is the increased interest in such new areas of Informatics as quantum computing and Bioinformatics. Therefore, it can be reasona- 
bly argued that the present line of work in this research become a key to the development of not only Informatics, but also many other areas of modern science.

The most urgent fundamental problems here are:

1. Investigation of the conceptual nature of information as one of the manifestations of the reality of the world around us.

2. The need for a more complete understanding of the role of information in the evolutionary proc esses that occur both in physical and biological systems, as well as in human society. There is reason to believe that the most fundamental laws of Informatics are common, both for physical and biological systems, and they determine the regularity of their evolution. This philosophical hypothesis is crucial for the whole system of modern science.

3. Current philosophical problem of Informatics is to identify and articulate the general laws of In formatics and to establish their relationship with the laws, which are exploring other fundamental sciences, such as General systems theory, Cybernetics, Synergetics, Quantum mechanics, Chemistry, Biology, Genetics, Psychology and Sociology. Work in this direction by Russian sci entists in recent years has been quite active.

4. Further development of basic scientific methods of Informatics: information approach, methods of simulation, as well as a deep virtual reality. These methods are expected to be brought to the fore in the methodology of scientific research as a science, and humanitarian areas of world sci ence in the next few years.

5. Actual scientific - methodological problems lie in the adequate positioning of Informatics in modern science. Today there is an objective need to review the current situation of Informatics in science and continue to characterize it as an independent branch of knowledge, which is a sci ence, and as something of humanitarian importance.

6. An important problem is the need to create a new, forward-looking structure of the subject area of Informatics, which would be more appropriate modern trends of development of science and education. Proposals on the structure have already been developed at the Institute of Informat ics Problems of the Russian Academy of Sciences. They are published in the scientific press and may serve as a real basis for scientific discussion and practical applications.

Studies show that the development of Informatics as an integrated scientific field can be a critical factor for the development of scientific and technological progress in the 21- st century.

\section{Philosophy of Information and Scientific Outlook}

Research in the philosophy of information field today is very relevant, because results are needed for the formation of the modern scientific worldview. It may be noted that, in recent years, these studies are beginning to take place in China. An analysis of relevant scientific, philosophical and methodological problems of modern science has shown that one of these problems is the problem of understanding the conceptual nature and essence of information.

According to many authoritative scholars, information is one of the most important and, at the same time, mysterious phenomena of the world around us. There have been attempts to comprehend the essence of this phenomenon by many researchers beginning in the mid 20th century. However, universally accepted ideas about the conceptual nature of information in science is still not yet developed. Therefore, these attempts are continuing today, in the 21th century, which is often called the information age.

Why do we still know so little about the nature of the information, the deep philosophical essence of the phenomenon and its fundamental relationship with the other philosophical sciences, such as matter and energy? In fact, many researchers have intuitively understood that these concepts are notions of a level of generality. Most likely, they indicate the most fundamental realities of the world around us. Perhaps the main reason here is that information is a multifaceted phenomenon. Therefore, it is specific to itself in terms of the implementation of various information processes, as well as at the different stages of their implementations. 
The structure of reality and the phenomenon of information. Kolin K.K. (2008) shows that the phenomenon of information is closely linked with the structure of reality and is the result of interaction between them forming the structure of material and ideal components.

At the same time, the author comes to the following main conclusions:

1. The structure of the reality of the world around us has a property dualism, since it simultaneously includes two main components - Physical reality and Ideal reality. Both of these components ex ist objectively and continuously interact with each other, as they possess the property of mutual reflection.

The ideal objective reality exists, regardless of the activity of consciousness, and is as an essen tial component of reality as physical reality. It arises from the interaction of objects (or process es), Physical reality manifests itself as a reflection of the properties of some objects (or proc esses) in the structure of other objects (or processes).

2. The ability of Physical reality and Ideal reality to mutually reflect their fundamental properties, actually creates the possibility of various aspects of the phenomenon of information. One of the first scientist, to point out the fundamental connection between the phenomena of reflection and information is A.D. Ursul.

3. Information is not a physical object or process and belongs to the world of ideal reality. However, to express its information, it needs objects (or processes) and physical reality to serve as its carriers. Without these objects (or processes), information shows itself to not be. The physical nature of media does not matter, in principle. It is only important that those carriers have the ability to perceive information through appropriate changes in their internal structure (for physical objects) or its parameters (for dynamic processes).

4. Despite the fact that information belongs to the world of ideal reality, its being associated with one physical object (or process) may affect the other object (or process) the physical world, which becomes the new bearer. This is realized through the mechanism of information transfer from one object (or process) physical reality to another.

5. In order to identify information related to some of its bearers (objects or processes of physical reality), there are special procedures, the most important of which is the procedure for compari son.

6. Information is one of the basic concepts of Informatics - the science of the principles and laws of the implementation of information processes in the systems of different nature. It is through the development and dissemination of Informatics that the concept of information greatly contributes today to the modern scientific picture of the world, based on the concept of unity of information laws and regularities.

All of this demonstrates the need for further philosophical reflection on the phenomenon of information and, above all, its conceptual nature and methods of systems in the physical and the ideal of reality, as well as its interactions with matter and energy.

Philosophical concept of open systems: Studies show that information is a major factor in the processes of self-organization and evolution of complex systems. This is true both for the living, and for natural beauty. Nevertheless, some philosophers are still debating the question of whether there is information in inanimate nature. Various scholars' answers to this question depends on the philosophical concept of views on the nature of the information they hold - or the same functional identity.

Supporters of a functional concept argue that the information represents only one of the functions of human consciousness, and, therefore, in inanimate nature, it cannot exist in principle. With respect to the laws of the functioning and development of natural beauty, they are quite well described by the relevant scientific disciplines (Physics, Chemistry and other sciences) in which the notion of information is little used.

This view is still widespread in science and in our days. However, while still open, there remain two basic issues. The first of these is how to combine the concept of functional information to the 
main provisions of the general theory of systems. In fact, according to this theory, not only functioning, but also the very existence of any system of stable organized structure implies interaction between its elements on the condition of their mutual exchange of information.

According to the concept of open systems, proposed by academician B.B. Kadomsev (1997), the whole world around us, from atomic structure to the galactic formations, is a nested set with different levels of hierarchical systems. These systems not only continually interact with each other on the energy level, but also carry out information interactions that are fundamentally necessary for their development.

The second issue is that even supporters of the functional concept still admit the existence of information in biological structures that do not possess consciousness (e.g., in the cells of living organisms and plants). Otherwise, how can we explain the principles of their genetic apparatus? In fact, all genetics, by its very nature, is a science of the origin, storage, transfer and change of genetic information. Thus, in both of the above principles, the concept of a functional nature of the information cannot currently provide any convincing answers.

Supporters of the same attributive concept, believe that information is an attribute of all objects as living or inanimate nature - their inherent property. This concept directs the attention of researchers to study aspects of the information, development, and interaction of all natural systems, including facilities and systems of an inanimate nature. This concept is more efficient because it encourages the new information hypothesis on the structure and evolution of natural systems.

In addition, the concept is fundamentally important for the development of theoretical foundations of computer science. After all, it allows for the analogy and makes necessary the results of studies of information processes and phenomena that take place in other scientific disciplines: physics, chemistry, biology, astronomy, earth sciences, etc.

Analysis of these results creates fundamentally new opportunities to identify common patterns in the information world around us and, therefore, to better understand its laws and use them in practical activities of people, including the creation of new tools and information systems, and the analysis and synthesis of biological and social processes and structures.

\section{Philosophy of Information and the Philosophical Foundations of Informatics}

Recent Russian studies of philosophical problems of Informatics have allowed scientists to formulate some regulations that can be seen as the philosophical foundations of Informatics as basic science and processes of information interactions in nature and society. Very briefly, these provisions may be stated as follows.

1. Information, in the broadest sense of the term, is an objective feature of reality that, manifests itself in the heterogeneity (asymmetry) of the distribution of matter and energy in space and time, the erratic course of all processes occurring in the world, animate and inanimate nature, as well as in human society and consciousness.

2. Information permeates all levels of organization of matter and energy in the world around us, it is the main reason for the movement of matter and energy, and it determines the direction of the movement of matter and energy in space and time.

3. Information is a crucial factor in evolution, it determines the direction of evolutionary processes in nature and society.

4. The amount of information is a measure of the complexity of organized systems of any nature and provides quantitative assessment of this complexity.

5. Information is a multifaceted phenomenon of reality that manifests itself in specific ways.

6. Studying these patterns should be one of the biggest challenges of Informatics as a fundamental science, and, therein, lies its interdisciplinary role in a system of scientific knowledge. 


\section{Philosophical Problems of Informatics in Education}

In the last decade, Informatics as basic science has become a key component of the entire system of scientific knowledge and will, to a large extent, determine the way of a global information society based on knowledge. In this regard, the increased interest in clarifying the status of Informatics in the sciences, as well as its fundamental historical and philosophical aspects observed today science and education, is clear. At the same time, education and training of scientific personnel of higher qualifications in Russia and other countries including the United States, are still dominated by an instrumental and technological approach to the study of Informatics, and many of its fundamental aspects are considered secondary.

Yet it is these aspects of scientific and methodological switching - the semiotic and philosophical foundation of Informatics-that are the most relevant today. They are necessary to improve the quality of training of scientific personnel and specialists of different profiles, as well as for the formation of a new information culture in a society adequate to the challenges of the 21- st century.

In recent years, the United States and Western Europe have reactivated interest in the scientific and methodological and educational aspects of Informatics. In 2005, the U.S. President was presented a special analytical report on these issues. Informatics is characterized as a strategically important area of science and practice necessary for the development of the economy, industry, high technology, national security, vocational education and training of scientific personnel.

The approach of the Russian scientists to study the problems of Informatics has always been more fundamental and comprehensive. Russia was first to form about the Informatics as basic science with important interdisciplinary, scientific, methodological and philosophical significance. At the 2- nd International UNESCO Congress "Education and Informatics" Russia proposed a new concept of studying the problems of Informatics as basic science and a general discipline in the system of advanced education. This was proposed as a new structure, and as a general course "The fundamentals of Informatics" for the future of the education system, and it was shown that the transition to this structure will be an important step towards the integration of basic science and education.

The study of the philosophical problems of Informatics today is a mandatory requirement in the training of graduate students and included in the candidate exam course "History and Philosophy of Science" approved by the Ministry of Education and Science of Russia. However, analysis of the content of this program showed that, while many of the current philosophical, scientific and methodological problems of Informatics are considered, this is not enough. Therefore, the Institute of Informatics Problems of the Russian Academy of Sciences developed a pilot program training course "Philosophical problem of Informatics", as well as a monograph that can serve as training tool for graduate students, masters and teachers of universities, has shown that it is of great interest students and help them develop not only a modern understanding of the fundamental problems of Informatics, but also a modern scientific worldview.

\section{Conclusion}

The study of philosophy and the philosophical problems of Informatics today is a very important and urgent need of science and education. In the study of the subject of Informatics as basic science, should be the basic properties of information, patterns of information exchange in nature and society, as well as methods of organizing the processes of technological, biological and social systems. Thus, science today is to examine not only the instrumental and technological challenges of collecting, storing, processing and transmitting information in computer information and communication and other technical systems, but also information processes in animate and inanimate nature, as well as in human society.

It is particularly relevant today to bring together scientists from various fields of science (Physics, Chemistry, Biology, Psychology, Informatics) to explore the features of information in biological systems, as well as in the processes of inanimate nature. Indeed, the results of these studies 
should enable scientists to identify common patterns that might be fair to information processes in the information media of different natures.

All of this should give man new opportunities for more effective organization of information processes, not only in technology but also in social systems. Based on this knowledge, people can more deeply explore the processes of vital activity of biological systems, as well as, perhaps, the principles of his conscience.

\section{References}

Gurevich I.M. (2003). Informatics Laws - A Basis of a Structure and Cognitive of Complex Systems. Moscow: Antikva. Kadomtsev B.B. (1997). Dynamics and Information. Moscow: Editorial Board of "Advances in Physical Sciences".

Kolin K.K. (2000). Informational Approach to the Methodology of Science and Scientific Outlook. Alma mater (Vestnik Vysshei Shkoly), 1, 16-22.

Kolin K.K. (2005 a). The Nature of Information and Philosophical Foundations of Informatics. Open Education, 2, $43-51$.

Kolin K.K. (2005 b). The Evolution of Informatics. Information Technologies, 1, 2-16.

Kolin K.K. (2006). The Formation of Informatics as Basic Science and Complex Scientific Problems. In K.Kolin (Ed.)

Systems and Means of Informatics. Special Issue. Scientific and Methodological Problems of Informatics. Moscow: IPI RAS, 7-57.

Kolin K.K. (2007 a). Philosophical, Scientific and Methodological Problems of Modern Science. Open Education, 3, 54-59.

Kolin K.K. (2007 b). Fundamental Studies in Informatics: A General Analysis, Trends and Prospects. Scientific and Technical Information, 1(7), 5-11.

Kolin K.K. (2007 c). The Experience of Studying the Problems of Informatics at Stanford University. Open Education, 2, 5263.

Kolin K.K. (2008). Structure of Reality and the Phenomenon of Information. Open Education, 5, 56-61.

Kolin K.K. (2010 a). The Structure and Content of the Course "Philosophical Problems of Informatics". In K.K. Kolin (Ed.), Philosophical Problems of Informatics (pp. 229-241). Moscow: BINOM.

Kolin K.K. (2010 b). Philosophical Problems of Informatics. Moscow: BINOM.

Liu Gang. (2007). Philosophy of Information and a Foundation for Future Chinese Philosophy of Science and Technology. Problems of Philosophy, 5, 45-57.

Ursul A.D. (1968). The Nature of the Information. Philosophical Essay. Moscow: Politizdat.

Ursul A.D. (1971). Information. Methodological Aspects. Moscow: Nauka.

Ursul A.D. (1973). Reflection and Information. Moscow: Nauka.

Ursul A.D. (1975). The Problem of Information in Modern Science: Philosophical Essays. Moscow: Nauka.

\section{About the Author}

Konstantin Kolin

Principal Researcher of the Institute of Informatics Problems of the Russian Academy of Sciences, Doctor of Technical Sciences, Professor, Honored Worker of Science of the Russian Federation.

E-mail:kolinkk@mail.ru 